\title{
Psychological Distress among Family Caregivers of Cancer Patients Khartoum State 2020
}

\author{
Osama $\mathrm{E}^{1 *}$, Kamil $\mathrm{S}^{2}$, Hiba $\mathrm{E}^{1}$ and Tahani $\mathbf{M}^{1}$ \\ ${ }^{1}$ Department of Community Medicine, National \\ University, Sudan \\ ${ }^{2}$ Department of Community Medicine, University of \\ Khartoum, Sudan \\ *Corresponding author: Elkhidir Osama, Department \\ of Community Medicine, National University, Sudan
}

Received: November 09, 2021; Accepted: December 01, 2021; Published: December 08, 2021

\begin{abstract}
Introduction: The incidence of cancer in Sudan, like other world, shows an increasing pattern; consequently, a greater number of people are expected to take the role of principal caregivers in the near future. Hence, it is high time to achieve inclusive knowledge about the outcome of caregiver burden related to the caregiver's well-being.
\end{abstract}

Materials and Methods: This study is a cross-sectional, observational study aiming to assess psychological distress among the principal family caregivers of cancer patients at oncology public specialized outpatients' clinics in Khartoum State. Multiple validated and structured questionnaires and a checklist were implemented to collect relevant data related to both cancer patient and family caregiver. Systematic random sample was applied to recruit 143 of cancer patients' caregivers.

Results: Majority of cancer patients were females $56.6 \%$ and $32.2 \%$ were in the age group (51-65) years. Breast cancer and leukemia were the most frequent types of cancer among participants, with $11.9 \%$ each. Regarding family caregiver most of them were females $54.5 \%$ with average age was (37.7) years. About half of them were the cancer patient's child descendants. Concerning psychological distress among family caregivers, depression and anxiety were reported by $(53.8 \%)$ and $(72.7 \%)$, respectively. Psychological distress is more prevalent among caregivers with subsequent characteristics: females, younger and middle age, and lower economic status.

Conclusion: Findings point to high proportions of elevated psychological distress, among family caregivers of cancer patients. Further, longitudinal studies with qualitative dimensions are recommended. Multidisciplinary arrangements are necessary to meet caregivers' needs.

Keywords: Anxiety; Caregiver burden; Depression; Family caregiver

\section{Abbreviations}

CES-D: Centre for Epidemiological Studies - Depression Scale; POMS: Profile of Mood States; SD: Standard Deviation; SPSS: Statistical Package for the Social Sciences; WHO: World Health Organization

\section{Introduction}

Nowadays cancer is widely considered as a global public health problem and one of the primary sources of death and suffering. It affects individuals at different ages in different countries around the world, irrespective of a country's economic level or population demography. In spite of noticeable advances in the health sector and medical technology during the last thirty years, incidence rates of cancer have shown escalating trends [1-3].

In the year 2015, international statistics established the significance of cancer as a second leading cause of death, just behind cardiovascular diseases which top the list. The World Health Organization (WHO) forecasts that cancer will cause additional burdens in the near future [4].

The estimation of the incidence of the disease is projected to surge from ten million in 2000 to 27 million in 2030, above and beyond additional 17 million deaths and 75 million individuals living with malignant neoplasms, most of which are in low-income countries $[5,6]$.

In accordance with existing statistics, cancer in Sudan shows an increasing trend during the last twenty years. Even though, no study reveals the exact reason for this trend, cancer may be associated with recurrent exposure to public and local carcinogens and to transformation in a way of living realised in Sudan. Population growth and aging also act as supplementary important risk factors [7-9].

More and more, cancer care is delivered in a home-based setting by means of the patient's family members taking up caregiving roles, supporting patients with daily activities and medical measures at home. Paradoxically, progress in cancer treatment has extended the life expectancy of cancer patients, with an expected additional load on family members $[10,11]$.

This clears up the fact that cancer diagnosis has significant impact, not only on the patients, but also on their family members and close ones. Individuals who go through the management of malignant disorders are profoundly confronted with considerable 
social, psychological, and financially draining experiences which affect those patients, alongside their families, relatives and friends [12]. The principal family caregiver is accountable for about $60-80 \%$ of the total home care received by the patient [13].

The word "caregiver" is a new terminology that covers a wide variety of practices and circumstances. Caregiving may possibly be informal; comprising caring for a family member or loved one within a home-based setting, or formal caregiving which is provided by medical professionals within an institutional setting [14].

Family caregivers so often face a wide array of stressors, comprising transformation in day-to-day activity, family role variations, own health settings, economic and work-related pressure. Those stressors help to explain the high prevalence of clinically elevated psychological distress among cancer patients' family caregivers. Family members have been considered as co-sufferers in the fight against malignant disorders $[15,16]$.

Healthcare experts and related institutes can greatly assist in alleviating the caregiver burden. Joint actions can be adopted to recognise, order caregiver burden and accordingly build appropriate interventions to this prevailing problem [17]

The aim of this study was to assess psychological distress in terms of "level of depression and anxiety" among the principal family caregivers of cancer patients.

\section{Materials and Methods}

\section{Study design}

A quantitative, descriptive cross sectional was applied. The study was conducted at oncology public specialized outpatients' clinics in Khartoum State. In fact, about $80 \%$ of patients diagnosed with cancer in Sudan received scheduled management at Khartoum Oncology Hospital $[7,18]$.

\section{Study Participants}

The study sample consisted of 143 caregivers whose patients had been diagnosed with cancer at least 3 months earlier than the time of data collection. The selection of patients was done through systematic random sampling by means of using cancer national registry. Then principal caregiver was identified as such by the cancer patient "care recipient", (the person who is responsible for majority of their unpaid, informal care).

\section{Data collection and measures}

A face-to-face interview was administered the same day consent was attained. The following instruments were employed in the interviews: Socio-demographic Questionnaire, Centre for Epidemiological Studies Depression Scale (CES-D)-10 items and Reduced Profile of Mood States (POMS)-Anxiety Subscale. In addition, patients' medical files were reviewed to record patients' medical information.

General information regarding family caregivers and cancer patients was gathered using a structured modified questionnaire. The questionnaire was divided into two sections, the first of which contained demographic, social, and economic data about the family caregiver. The second section featured information on cancer patients' demographics and medical conditions. Clinical data on disease type, stage, and management method were extracted from patients' medical records.

The CES-D-10 is considered as a satisfactory psychological measure in both healthy and mentally ill individuals. Overall scale scores vary between 0 and 30 [19-21].

The POMS questionnaire is a standard authenticated psychometric test used in research [22]. In this study, POMS anxiety subscale was implemented to minimise participant and researcher loads. (POMS) subscale scores range between 0 and 12 [23].

\section{Data management and analysis}

Statistical Package for the Social Sciences (SPSS) version 20 was used for data entry and statistical analysis. Percentages, frequencies, means, and standard deviations were used to characterise demographic and medical information of cancer patients and principal caregivers' socio-demographic characteristics, level of anxiety and depression. A 2 -sided $\mathrm{P}$ value $<.05$ was considered statistically significant.

\section{Results}

\section{Cancer patients' characteristics}

In this study, females made up a slight majority of cancer patient $56.6 \%$. The female to male ratio was $1.3: 1$, almost similar figures were observed similar studies regarding gender distribution of cancer in Sudan. Similarly, age distribution in the study samples reflected actual same age distribution among Sudanese cancer patients. Middle age categories were the most affected groups [7,24,25] (Table 1).

Regarding to cancer type, breast cancer and leukaemia were found to be at the top of the list, followed by lymphoma, gastric and endometrial cancer. Likewise, this distribution resembled, with few exceptions, the representative distribution of cancer among general population in Sudan as revealed by Cancer Registry $[25,26]$. Different pattern of cancer was realized in studies conducted in other developing and developed countries in global statistics related to cancer distribution [27,28] (Table 2).

\section{Family caregivers' characteristics}

As regards to caregivers' characteristics; most of them were middle aged family members with mean age of 37.7 years old. Many studies which were conducted in several countries, demonstrated the common stream of higher average age of family caregivers' equivalents to 50 years or more $[10,28,29]$. Few exceptions were found in particular studies, where the mean age of family caregiver was around 42 years [30]. This could be explained by the divergences in social background and familial context (Table 3).

Table 1: General characteristics of cancer patients, Khartoum Oncology Hospital, $2018(n=143)$.

\begin{tabular}{|c|c|c|c|}
\hline Variable & Category & Count (\%) & \multirow{2}{*}{ Mean (SD) } \\
\hline \multirow{4}{*}{ Age } & $0-17$ & $9(6.3)$ & \multicolumn{1}{|c|}{} \\
\cline { 2 - 3 } & $18-34$ & $25(17.5)$ & \multirow{2}{*}{$49.1(19.2)$} \\
\cline { 2 - 3 } & $35-50$ & $36(25.2)$ & \multirow{2}{*}{} \\
\cline { 2 - 3 } & $51-65$ & $46(32.2)$ & \multicolumn{1}{|c}{-} \\
\cline { 2 - 3 } & $>65$ & $27(18.9)$ & \\
\hline \multirow{3}{*}{ Gender } & Male & $62(43.4)$ & \\
\cline { 2 - 3 } & Female & $81(56.6)$ & \\
\hline
\end{tabular}


Table 2: Disease related characteristics of cancer patients, Khartoum Oncology Hospital, $2018(n=143)$.

\begin{tabular}{|c|c|c|c|}
\hline & & & \\
\hline Variable & Category & Count (\%) & $\%$ \\
\hline \multirow{16}{*}{ Type of cancer } & Breast cancer & 17 & 11.9 \\
\hline & Liver cancer & 4 & 2.8 \\
\hline & Leukemia & 17 & 11.9 \\
\hline & Lymphoma & 14 & 9.8 \\
\hline & Ovarian cancer & 11 & 7.7 \\
\hline & Endometrial cancer & 12 & 8.4 \\
\hline & Gastric cancer & 9 & 6.3 \\
\hline & Colon cancer & 7 & 4.9 \\
\hline & Rectal cancer & 5 & 3.5 \\
\hline & Malignant melanoma & 5 & 3.5 \\
\hline & Cervical cancer & 3 & 2.1 \\
\hline & Prostate cancer & 3 & 2.1 \\
\hline & Nasopharyngeal cancer & 4 & 2.8 \\
\hline & Oral cavity cancer & 4 & 2.8 \\
\hline & Multiple myeloma & 3 & 2.1 \\
\hline & Others & 25 & 17.5 \\
\hline \multirow{4}{*}{ Stage of disease } & Stage I & 32 & 22.9 \\
\hline & Stage II & 30 & 21.4 \\
\hline & Stage III & 32 & 22.9 \\
\hline & Stage IV & 46 & 32.9 \\
\hline \multirow{6}{*}{ Type of treatment } & Chemotherapy & 76 & 53.9 \\
\hline & Radiotherapy & 6 & 4.3 \\
\hline & Surgery & 2 & 1.4 \\
\hline & Chemotherapy + Surgery & 23 & 16.3 \\
\hline & $\begin{array}{c}\text { Chemotherapy + Radiotherapy + } \\
\text { Surgery }\end{array}$ & 6 & 4.3 \\
\hline & Other & 28 & 19.9 \\
\hline
\end{tabular}

Table 3: Demographic characteristics of family caregiver of cancer patients, Khartoum Oncology Hospital, $2018(n=143)$.

\begin{tabular}{|c|c|c|c|}
\hline Variable & Category & Count (\%) & Mean (SD) \\
\hline \multirow{4}{*}{ Age } & $18-34$ & $68(47.6)$ & \multirow{4}{*}{$37.7(13.2)$} \\
\hline & $36-50$ & $48(33.6)$ & \\
\hline & $51-65$ & $24(16.8)$ & \\
\hline & $>65$ & $3(2.1)$ & \\
\hline \multirow{2}{*}{ Gender } & Male & $65(45.5)$ & \multirow{2}{*}{-} \\
\hline & Female & $78(54.5)$ & \\
\hline \multirow{6}{*}{ Original residence } & Khartoum & $51(35.7)$ & \multirow{6}{*}{-} \\
\hline & Darfur & $14(9.8)$ & \\
\hline & Kordofan & $28(19.6)$ & \\
\hline & East states & $7(4.9)$ & \\
\hline & Central and southern states & $35(24.5)$ & \\
\hline & Northern states & $8(5.6)$ & \\
\hline
\end{tabular}

Regarding, social characteristics of family caregivers, about half of them were the cancer patient's child (mainly patient's son), about $20 \%$ were the patient's siblings, and only $14 \%$ were the patient's
Table 4: Social characteristics of family caregiver of cancer patients, Khartoum Oncology Hospital, $2018(n=143)$.

\begin{tabular}{|c|c|c|c|}
\hline Variable & Category & Count (\%) & Mean (SD) \\
\hline \multirow{8}{*}{$\begin{array}{c}\text { Relation of caregiver to cancer } \\
\text { patient }\end{array}$} & Father & $6(4.2)$ & \multirow{8}{*}{-} \\
\hline & Mother & $16(11.2)$ & \\
\hline & Son & $40(28.0)$ & \\
\hline & Daughter & $32(22.4)$ & \\
\hline & Brother & $12(8.4)$ & \\
\hline & Sister & $17(11.9)$ & \\
\hline & Husband & $7(4.9)$ & \\
\hline & Wife & $13(9.1)$ & \\
\hline \multirow{6}{*}{ Educational level } & Illiterate & $29(20.3)$ & \multirow{6}{*}{-} \\
\hline & Khalwa & $11(7.7)$ & \\
\hline & Primary & $30(21.0)$ & \\
\hline & Secondary & $42(29.4)$ & \\
\hline & University & $7(4.9)$ & \\
\hline & Post Graduate & $24(16.8)$ & \\
\hline \multirow{4}{*}{ Marital status } & Single & $42(29.4)$ & \multirow{4}{*}{-} \\
\hline & Married & $90(62.9)$ & \\
\hline & Divorced & $1(0.7)$ & \\
\hline & Widowed & $10(7.0)$ & \\
\hline \multirow{3}{*}{ Number of children } & 2-Jan & $22(24.2)$ & \multirow{3}{*}{$3.2(2.8)$} \\
\hline & 5-Mar & $35(38.5)$ & \\
\hline & $>5$ & $34(37.4)$ & \\
\hline
\end{tabular}

Table 5: Prevalence of depression and anxiety among family caregiver of cancer patients using (CES-D) and POM - Anxiety subscale, Khartoum Oncology Hospital, $2018(n=143)$.

\begin{tabular}{|c|c|c|c|}
\hline Item & Category & Count & $\%$ \\
\hline \multirow{2}{*}{ Depression } & Present & 77 & 53.8 \\
\cline { 2 - 4 } & Absent & 66 & 46.2 \\
\hline \multirow{2}{*}{ Anxiety } & Present & 104 & 72.7 \\
\cline { 2 - 4 } & Absent & 39 & 27.3 \\
\hline
\end{tabular}

spouses. Around $30 \%$ of family caregivers accomplished secondary school, one fifth finished their primary education, and an equal portion received no formal education (Table 3).

\section{Family caregivers' psychological distress}

By using Shortened Centre for Epidemiological StudiesDepression Scale and Profile of Mood States-anxiety subscale, depression was established in more than half of the family caregivers $53.8 \%$ and anxiety in $72.7 \%$, (Table 4 ).

\section{Discussion}

Nearly this study revealed the same epidemiological picture of cancer in Sudan with regard age distribution, gender affiliation and cancer type and management modality [7,31].

Expectedly, females had dominant contribution as a family caregiver which was supported by many studies completed in different parts of the globe $[10,30,32,33]$. Those results were consistent with the leading social role of the woman almost in all cultures, irrespective of 
Table 6: Chi square results to test significance of association between depression status among family caregiver and family caregiver characteristics, Khartoum Oncology Hospital, $2018(n=143)$.

\begin{tabular}{|c|c|c|c|c|}
\hline \multirow{2}{*}{ Item } & \multirow{2}{*}{ Category } & $\begin{array}{c}\text { Not } \\
\text { depressed }\end{array}$ & Depressed & \multirow[t]{2}{*}{ P.value } \\
\hline & & Count (\%) & Count (\%) & \\
\hline \multirow{2}{*}{ Caregiver gender } & Male & $31(47.7)$ & $34(52.3)$ & \multirow{2}{*}{0.433} \\
\hline & Female & $35(44.9)$ & $43(55.1)$ & \\
\hline \multirow{4}{*}{ Caregiver age } & $18-34$ & $32(47.1)$ & $36(52.9)$ & \multirow{4}{*}{0.333} \\
\hline & $36-50$ & 18 (37.5) & $30(62.5)$ & \\
\hline & $51-65$ & $14(58.3)$ & $10(41.7)$ & \\
\hline & $>65$ & $2(66.7)$ & $1(33.3)$ & \\
\hline \multirow{4}{*}{ Marital status } & Single & $21(50.0)$ & $21(50.0)$ & \multirow{4}{*}{0.736} \\
\hline & Married & $41(45.6)$ & $49(54.4)$ & \\
\hline & Divorced & $0(0.0)$ & $1(100.0)$ & \\
\hline & Widowed & $4(40.0)$ & $6(60.0)$ & \\
\hline \multirow{6}{*}{$\begin{array}{l}\text { Caregiver monthly gross } \\
\text { income }\end{array}$} & $0-450$ & $18(36.0)$ & $32(64.0)$ & \multirow{6}{*}{0.058} \\
\hline & $451-1500$ & $17(42.5)$ & $23(57.5)$ & \\
\hline & $1501-3000$ & $15(50.0)$ & $15(50.0)$ & \\
\hline & $3001-5000$ & $7(53.8)$ & $6(46.2)$ & \\
\hline & $\begin{array}{l}5001- \\
10000\end{array}$ & $6(85.7)$ & $1(14.3)$ & \\
\hline & $>10000$ & $3(100.0)$ & $0(0.0)$ & \\
\hline \multirow{6}{*}{$\begin{array}{l}\text { Household monthly gross } \\
\text { income }\end{array}$} & $0-450$ & $3(33.3)$ & $6(66.7)$ & \multirow{6}{*}{0.023} \\
\hline & $451-1500$ & $9(31.0)$ & $20(69.0)$ & \\
\hline & $1501-3000$ & $14(38.9)$ & $22(61.1)$ & \\
\hline & $3001-5000$ & $12(44.4)$ & $15(55.6)$ & \\
\hline & $\begin{array}{l}5001- \\
10000\end{array}$ & $18(60.0)$ & $12(40.0)$ & \\
\hline & $>10000$ & $10(83.3)$ & $2(16.7)$ & \\
\hline
\end{tabular}

Table 7: Correlation between depression status and anxiety status, Khartoum Oncology Hospital, 2018 ( $n=143$ )

\begin{tabular}{|c|c|c|c|}
\hline \multicolumn{2}{|c|}{ Item } & Depression & Anxiety \\
\hline \multirow{2}{*}{ Depression } & $r$ & \multirow{2}{*}{1} & $0.710^{\star \star}$ \\
\cline { 2 - 2 } & P-value & & $<0.001$ \\
\hline \multirow{2}{*}{ Anxiety } & $r$ & $0.710^{\star *}$ & 1 \\
\cline { 2 - 4 } & P-value & $<0.001$ & \\
\hline
\end{tabular}

${ }^{*}$ Correlation is significant at the 0.01 level (2-tailed).

community structure or economic status of the country. Furthermore, the leading economic role of men may appear as a factor to inhibit their caregiving role. This economic justification can possibly be supported by the result that, more than one third of family caregivers were households.

In the same context, this study showed that almost half of the family caregivers were patients descendent $50.4 \%$ and $15 \%$ were patients' spouses. Inversely, several studies revealed that patients' partners and spouses are the chief family caregivers $[16,28]$. This point shows another area of discrepancy in social norms that regulate the characteristics of family caregiver.

In this study, depression was reported by $54 \%$ of family caregivers. This result is aligned with the depression prevalence established in equivalent studies, which demonstrated a variation in depression prevalence between $40 \%$ up to $60 \%$ [15]. However, some studies revealed prevalence of depression among family caregivers less or more than above stated range [34]. Generally, studies had displayed a widespread of depression prevalence among family caregivers; e.g. a wide-range from $4.5 \%$ to $(82.2 \%)$ [35].

On the other hand, anxiety was more prevalent among family caregivers. It was reported by $(73 \%)$ of participants. This result was relatively high compared to similar studies. For instance, an American study revealed anxiety prevalence of $42.2 \%$ and an Indian study showed anxiety prevalence of $53 \%[34,36]$.

Depression among family caregivers was correlated to household income, whereas anxiety was interconnected to caregiver gender, age and income. Psychological distress is more prevalent among caregivers with subsequent characteristics: females, younger and middle age and with lower economic status, this was in keeping with existing literature [15]. Higher prevalence of psychological distress among females may be explained by the fact that women carry out different family tasks besides caregiving job [34,37].

This study showed that, psychological distress (depression and anxiety) among family caregivers was positively correlated to each other. Anxiety and depression symptoms are common negative psychological consequences that emerge from cancer caregiving. In comparison to the general population, family carers have reported higher levels of anxiety and depression [38]. Individual and social rules that may not line up with or emotionally support the patient and family experiencing and responding to the many core symptoms of depression, such as depressed and abrupt mood swings, anhedonia, and sometimes uncontrollable and violent outbursts, are likely to complicate the caregiving experience [33].

This study, however, had some limitations. Firstly, although the standardized tools used in this study to assess different aspects of family caregiver burden are very much valid and reliable in many societies, limitation may be present when addressing tool's reliability on Sudanese population. This issue may be a concern to construction of the tool, a selection of variables, diagnostic criteria and cut off points.

Secondly, some of individual criteria which may affect caregiving burden, particularly level of psychological distress such as personal trait and personality type were not measured. Deficiencies in time and application complexity of those measurements were major constraints.

\section{Conclusion}

The findings point out an elevated psychological distress among family caregivers of cancer patients, with relative to recognizable high anxiety level. Numerous patients' and family caregivers' qualities have a role as determining factors in generating family caregiver burden. At the level of policy formulation, multidisciplinary arrangements are necessary to adopt firm regulations to meet caregivers' psychological requirements. In addition, timely strengthening of oncology centres to offer specialized service to family caregiver of cancer patients is crucial.

\section{References}

1. Sung H, Ferlay J, Siegel RL, Laversanne M, Soerjomataram I, Jemal A, et 
al. Global cancer statistics 2020: GLOBOCAN estimates of incidence and mortality worldwide for 36 cancers in 185 countries. CA: a cancer. Journal for clinicians. 2021; 71: 209-249.

2. Kulhánová I, Bray F, Fadhil I, Al-Zahrani AS, El-Basmy A, Anwar WA, et al Profile of cancer in the Eastern Mediterranean region: The need for action. Cancer epidemiology. 2017; 47: 125-132.

3. Gostin LO, Wiley LF. Public health law: power, duty, restraint: Univ of California Press. 2016

4. Rugge M, Fassan M, Graham DY. Epidemiology of gastric cancer. Gastric Cancer: Springer. 2015; 23-34.

5. Global Burden of Disease Cancer C. The global burden of cancer 2013 JAMA oncology. 2015; 1: 505-527.

6. Oliveira MdBPd, Souza NRd, Bushatsky M, DÃ maso BFR, Bezerra DM, Brito JAd. Oncological homecare: family and caregiver perception of palliative care. Escola Anna Nery. 2017; 21; 30

7. Saeed MEM, Cao J, Fadul B, Kadioglu O, Khalid HE, Yassin Z, et al. A fiveyear survey of cancer prevalence in Sudan. Anticancer research. 2016; 36: 279-286

8. Hassanin AA, Idris AM. Attribution of oral cancer in the Sudan to Toombak dipping. Translational Research in Oral Oncology. 2017; 2.

9. Elamin A, Ibrahim ME, Abuidris D, Mohamed KEH, Mohammed SI. Part I: cancer in Sudan - burden, distribution, and trends breast, gynecological, and prostate cancers. Cancer medicine. 2015; 4: 447-456.

10. Stenberg U, Ruland CM, Miaskowski C. Review of the literature on the effects of caring for a patient with cancer. Psycho - oncology. 2010; 19: 1013-1025

11. Stajduhar KI, Davies B. Variations in and factors influencing family members decisions for palliative home care. Palliative Medicine. 2005; 19: 21-32.

12. Üzar-Özçetin YS, Dursun Sì. Quality of life, caregiver burden, and resilience among the family caregivers of cancer survivors. European Journal of Oncology Nursing. 2020; 48: 101832.

13. Pauley T, Chang BW, Wojtak A, Seddon G, Hirdes J. Predictors of Caregive Distress in the Community Setting Using the Home Care Version of the Resident Assessment Instrument. Professional case management. 2018; 23 : 60-69

14. Hermanns M, Mastel-Smith B. Caregiving: A qualitative concept analysis The Qualitative Report. 2012; 17: 1.

15. Rhee YS, Yun YH, Park S, Shin DO, Lee KM, Yoo HJ, et al. Depression in family caregivers of cancer patients: the feeling of burden as a predictor of depression. Journal of Clinical Oncology. 2008; 26: 5890-5895.

16. Mosher CE, Champion VL, Azzoli CG, Hanna N, Jalal SI, Fakiris AJ, et al. Economic and social changes among distressed family caregivers of lung cancer patients. Supportive Care in Cancer. 2013; 21: 819-826.

17. Reinhard SC, Given B, Petlick NH, Bemis A. Supporting family caregivers in providing care. 2008

18. Ahmed M, Ali Z, El Higaya E, Ibrahim N, Flavin A, Abuidris DO. Oncology Services in Sudan: Realities and Ambitions. A joint conference of the Sudanese Medical Association (UK \& Ireland) and the National Cancer Institute in Medani, Sudan in collaboration with the Sudanese Oncology Society; Medani, Gezira State, Sudan. 2013.

19. Lundgren O, Garvin P, Andersson G, Jonasson L, Kristenson M. Inverted items and validity: A psychobiological evaluation of two measures of psychological resources and one depression scale. Health psychology open. 2018; 5: 2055102918755045

20. González P, Alicia N, Merz E, Brintz C, Weitzman O, Navas EL, et al. Measurement properties of the Center for Epidemiologic Studies Depression Scale (ces-d 10): Findings from Hchs/sol. Psychological assessment. 2017; 29: $372-381$

21. Björgvinsson T, Kertz SJ, Bigda-Peyton JS, McCoy KL, Aderka IM Psychometric properties of the CES-D-10 in a psychiatric sample. Assessment. 2013; 20: 429-436.
22. Nyenhuis DL, Yamamoto C, Luchetta T, Terrien A, Parmentier A. Adult and geriatric normative data and validation of the profile of mood states. Journal of clinical psychology. 1999; 55: 79-86.

23. Bradley SE. Economic hardship and the emotional health of family caregivers: University of Pittsburgh. 2008

24. Mohammed ME, Hassan AM, Abdelhadi HA, Elsadig MG, Adam DM, Elmamoun K, et al. Burden and pattern of cancer in the Sudan, 2000-2006 British Journal of Medicine and Medical Research. 2014; 4: 1231-1243.

25. Saeed IE, Weng HY, Mohamed KH, Mohammed SI. Cancer incidence in Khartoum, Sudan: first results from the Cancer Registry, 2009 - 2010. Cancer medicine. 2014; 3: 1075-1084.

26. Omar S, Alieldin NHM, Khatib OMN. Cancer magnitude, challenges and control in the Eastern Mediterranean region. 2007; 13: 1486-1496.

27. Bray F, Ferlay J, Soerjomataram I, Siegel RL, Torre LA, Jemal A. Globa cancer statistics 2018: GLOBOCAN estimates of incidence and mortality worldwide for 36 cancers in 185 countries. CA: a cancer journal for clinicians. 2018; 68: 394-424.

28. Kim SY, Shin DW, Park B, Cho J, Oh JH, Kweon SS, et al. Cancer cost communication: experiences and preferences of patients, caregivers, and oncologists - a nationwide triad study. Supportive Care in Cancer. 2018; 26: 3517-3526

29. Shin DW, Cho J, Roter DL, Kim SY, Park JH, Yang HK, et al. Patients' cognitive function and attitudes towards family involvement in cancer treatment decision making: A patient-family caregiver dyadic analysis. Cancer research and treatment: official journal of Korean Cancer Association. 2018; 50: 681-690.

30. Oven Ustaalioglu B, Acar E, Caliskan M. The predictive factors for perceived social support among cancer patients and caregiver burden of their family caregivers in Turkish population. International journal of psychiatry in clinical practice. 2018; 22: 63-69.

31. Gafer N, Walker E, Allah MK, Elbaghir A. Cancer Care in Sudan: Current Situation and Challenges. Cancer Care in Countries and Societies in Transition: Springer. 2016; 209-217.

32. Maguire R, Hanly P, Hyland P, Sharp L. Understanding burden in caregivers of colorectal cancer survivors: what role do patient and caregiver factors play? European journal of cancer care. 2018; 27: e12527.

33. Balkaran B, Jaffe D, Umuhire D, Rive B, Milz R. Self-reported burden of caregiver of adults with depression: a cross-sectional study in five Western European countries. BMC psychiatry. 2021; 21: 312.

34. Santre MS, Jyoti R, Sainath M. Prevalence of emotional distress in caregiver's of cancer patients. International Journal of Medical Research and Health Sciences. 2014; 3: 675-683

35. Lee C-Y, Lee Y, Wang L-J, Chien C-Y, Fang F-M, Lin P-Y. Depression, anxiety, quality of life, and predictors of depressive disorders in caregivers of patients with head and neck cancer: A six-month follow-up study. Journal of psychosomatic research. 2017; 100: 29-34.

36. Nipp RD, El-Jawahri A, Fishbein JN, Gallagher ER, Stagl JM, Park ER, et al. Factors associated with depression and anxiety symptoms in family caregivers of patients with incurable cancer. Annals of Oncology. 2016; 27 : 1607-1612

37. Dumont S, Turgeon J, Allard P, Gagnon P, Charbonneau Cécile, Lucie V Caring for a loved one with advanced cancer: determinants of psychological distress in family caregivers. Journal of Palliative Medicine. 2006; 9: 912-921.

38. Finocchiaro CY, Petruzzi A, Lamperti E, Botturi A, Gaviani P, Silvani A, et al The burden of brain tumor: a single-institution study on psychological patterns in caregivers. Journal of neuro-oncology. 2012; 107: 175-181. 